\title{
SPECTRAL ANALYSIS OF OUTPUT VOLTAGES AND CURRENTS AS A CRITERION FOR TECHNICAL DIAGNOSTICS OF SYNCHRONOUS GENERATORS OF SHIP DIESEL ENGINE
}

\author{
A. Gasparjans*, A. Terebkov, V. Priednieks, R. Klaucans \\ Latvian Maritime Academy, \\ 5b Flotes Str., Riga, LV-1016, LATVIA, \\ *e-mail: aleksandrs.gasparjans@latja.Iv
}

Diesel generator sets (DGU) are very widely used in autonomous power supply systems. An example is marine power plants, diesel locomotives with electric power transmission, uninterruptible power supply units, etc. The power of ship DGUs reaches 2-6 or more MW in one unit. The number of units on ships can be different, but, as a rule, at least two. In this paper, we propose a method of monitoring the dynamic electromechanical system "diesel synchronous generator". The method aims at using a synchronous generator machine as a multifunctional accurate and sensitive sensor for diagnostic parameters of the electromechanical system. The proposed method of technical diagnostics is based on continuous monitoring of non-uniformity of diesel torque, fluctuations in the instantaneous angular velocity and instantaneous angular acceleration of the diesel crankshaft. These data are the results of a spectral analysis of stator currents and voltages of a synchronous generator.

Keywords: acceleration, angular velocity, diagnostics, diesel, generator, spectrum, stator current, voltage,.

\section{INTRODUCTION}

Currently, there are a lot of autonomous DGUs operating in transport (river and sea vessels, drilling platforms, diesel locomotives with electric power transmission, etc.), uninterruptible power supply units and emergency units, the normal functioning of which depends on people's lives, economic efficiency and environmental 
protection. These diesel generator sets are not connected to an industrial centralized power supply network. In this regard, it is very important to maintain the diesel generator set in a normal, technical condition, in accordance with the given parameters. A decisive role is played by timely technical diagnostics, which can timely prevent the development of emergency situations. It can convert sudden failures into a gradual discharge, determine the residual motor resource of the unit. For example, the issues of monitoring and diagnosing of diesel plant are discussed in detail [1]-[5] and diesel generator sets with synchronous generators are considered in [6], [7], [14], [15]. A significant part of the works [8]-[12] describes the application of vibration diagnostics methods. Along with the advantages of this method, there are some disadvantages. For example, access to the necessary components and assemblies is not always available; highly qualified personnel are required. Not all mechanisms and units are prepared at the factory for vibrodiagnostics.

The proposed version of technical diagnostics for monitoring the spectral energy composition of stator currents and voltages of a synchronous generator allows for diagnostics of both a synchronous generator and a diesel engine. The article proposes a method for the technical diagnosis of diesel power plants, in which the spectral and energy characteristics of higher harmonics of the output voltage and current are used as diagnostic parameters. The fundamentals of this method were presented by the authors in articles [8]-[11]. It became possible in connection with the rapid development of measuring, storage and processing of information, including microprocessor technology. Previously, such an analysis was carried out most often up to 5-7 harmonics of voltage and current. Harmonics of higher orders in view of their insignificant size and measurement difficulties were usually not considered. The advent of modern highspeed multi-bit analogue-to-digital converters (ADCs) makes it possible to measure the spectral energy characteristics of higher order harmonics up to $11 \ldots$ 15th with an amplitude of $2 \% \ldots 0.2 \%$ of the amplitude of the fundamental harmonic. The use of mathematical methods makes it possible to identify the place and cause of their occurrence. Thus, the spectral energy characteristics of higher harmonics can be taken as diagnostic parameters. Comparison of the parameters of higher harmonics with reference values can significantly expand the capabilities of technical diagnostic systems. The unevenness of the torque, instantaneous fluctuations in the angular velocity and instantaneous angular frequency lead to a change in the parameters of the electromagnetic process in the generator, changes in the nature of the interaction of the rotor and stator of the generator. In this case, the spectral composition of the output currents and voltages changes. Higher harmonic components are the product of the electromagnetic interaction of the rotor and stator of an electric machine. The nature of this interaction depends not only on the parameters of the electric machine, but also on the mechanical characteristics of the drive motor - its instantaneous angular frequency of rotation and instantaneous angular acceleration. These parameters characterise the technical condition of the drive motor. Such measurements have their own specifics and, in terms of accuracy, are, in fact, laboratory measurements.

The uneven torque, instantaneous oscillation angular velocity and the angular frequency lead to a change in electromagnetic flow process parameters in the generator, the changing nature of interaction of the rotor and stator of the generator. In this case, the spectral composition of the 
output currents and voltages changes. The present article proposes a method of technical diagnostics based on continuous monitoring of non-uniformity of diesel torque, fluctuations in instantaneous angular velocity and angular acceleration for one or two revolutions of the diesel crankshaft. The data obtained are compared either with reference values or with values obtained as a result of mathematical modelling. Deviations of the parameters of these irregularities from the reference characterise the state of the cylinder-piston group (CPG) of the diesel engine and the quality of the working process in its cylinders. The second feature of this method is the use of a standard generator of a diesel-electric installation as a multifunctional sensor. It is possible to diagnose by the balance of the instantaneous power of the diesel engine and the generator - to determine the instantaneous power of the diesel engine, to compare it with the reference values corresponding to the given position of the rail of the fuel pump depending on the generator load. The unevenness of the torque, fluctuations in the angular velocity and angular acceleration of the diesel crankshaft are due to both the specifics of the flow of the working process and its quality in its cylinders, and the specifics of converting the reciprocating motion of the piston into a rotary motion of the crankshaft. The proposed method refers to non-destructive testing methods, most often it does not require a long shutdown of equipment and is performed in real-life conditions. Connection to the generator output terminals is made either on the generator itself or on its control panel.

For technical diagnostics, it is required to install a top dead centre sensor (TDC) and an instantaneous angular velocity sensor in the diesel flywheel area. TDC sensor signals can also be obtained from the electronic control system of the diesel generator itself. In most cases, the DGU control system does not determine the instantaneous angular velocity. Usually it is considered as the transit time of the TDC of the first cylinder for a certain period of time. However, the instantaneous angular velocity and instantaneous angular acceleration, even in multi-cylinder diesel engines, are not constant for one revolution of the crankshaft. It is the oscillations of the instantaneous angular velocity of rotation and angular instantaneous acceleration that are the diagnostic parameters adopted in this method. Knowing the number of engine cylinders and the order of their operation, it is possible to accurately determine in which cylinder the fuel combustion process is damaged, to identify defects in the generator bearings, braking of the generator rotor and engine crankshaft due to partial windings (distortion of the magnetic field in the generator air gap), etc. The instantaneous angular velocity sensor can be installed against the teeth of the gearwheel of the engine flywheel or the teeth of the gear shaft mechanism on ships. Installing voltage sensors and current sensors is not complicated. Often, one can use existing sensors in the existing control circuit of the diesel generator set.

\section{MATHEMATICAL MODEL OF THE SYSTEM DIESEL ENGINE GENERATOR}

The equation of motion of a diesel generator in general form can be written as follows (the basic equation of the electric drive): 
$\left(J_{d}+J_{g e n}\right) * \frac{d \omega_{g e n}(t)}{d t}=T_{d}(t)-T_{g e n}(t)$

where $T_{\text {gen }}(t)=k_{\text {mgen }} \Phi_{\text {gen }}(t) \cdot i(t)$ - the torque formed by the synchronous generator (SG);

$T_{d}$ - rms value of the rotational torque of diesel;

$J_{d}-$ the moment of inertia of diesel reduced to the crank shaft;

$J_{g e n}-$ the moment of inertia of generator;

$\omega_{\text {gen }}(t)$ - angular velocity of diesel generator;

$k_{\text {mgen }}$ - the constructive constant of the generator;

$\Phi_{g e n}-$ magnetic flux of generator.

\section{MATHEMATICAL MODEL OF DIESEL}

In this case, the model [6], [17], [18] with the corresponding changes can be taken as the basis of the mathematical (differential) model of a diesel engine with gas turbine supercharging. The basis of the mathematical model is a system of differential equations of the mass and energy balance of the working fluid and the equation of state. In general, the mathematical model can be represented as follows:

Turbocharger: $J_{k} \frac{d \omega_{k}}{d t}=T_{t}-T_{k}$

Diesel engine: $\frac{d(\omega+\varepsilon(t))}{d t}=T_{i}-T_{p}-T_{g e n}$

Intake manifold: $\frac{V_{i, m}}{R_{b} T_{\kappa}{ }^{0}} \cdot \frac{d p_{k}}{d t}=G_{k}-G_{d}$

Exhaust manifold: $\frac{V_{e . m}}{R_{g} T_{g}{ }^{0}} \cdot \frac{d p_{t}}{d t}=G_{g}-G_{t}$,

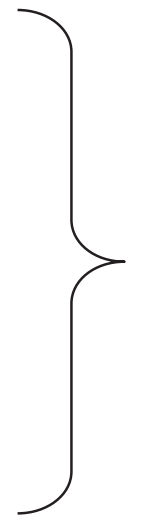

where $J_{k}$-moment of inertia of the compressor;

$T_{t}$ - turbine torque, $T_{t}=T_{t}\left(\omega, \omega_{k}, B\right)$;

$T_{k}-$ moment of resistance of the compressor, $T_{k}=T_{k}\left(Q, \omega_{k}\right)$;

$T_{i}$ - indicator torque of the diesel;

$T_{p}-$ moment of diesel loss;

$T_{\text {gen }}^{p}$ - braking torque on the diesel shaft from the generator (load moment);

$\omega_{k}$ - angular velocity of the rotor of the turbo compressor;

$\omega$ - angular velocity of the crankshaft of the diesel engine (generator shaft);

$\varepsilon$ - deviation of the angular velocity of the crankshaft;

$V_{i . m}$ - intake manifold volume;

$V_{e . m}$ - exhaust manifold volume;

$R_{B}-$ gas constant of charge air;

$R_{g}{ }_{g}-$ gas constant of the exhaust gases; 
$T_{k}^{0}$ - temperature of the charge air;

$T_{g}^{0}$ - temperature of the exhaust gases;

$G_{k}$ - air flow through the compressor of the turbocharger;

$G_{d}$ - air flow through the engine;

$G_{g}$ - exhaust gas flow through the engine;

$G_{t}$ - flow rate of exhaust gases through the turbine of the turbocharger.

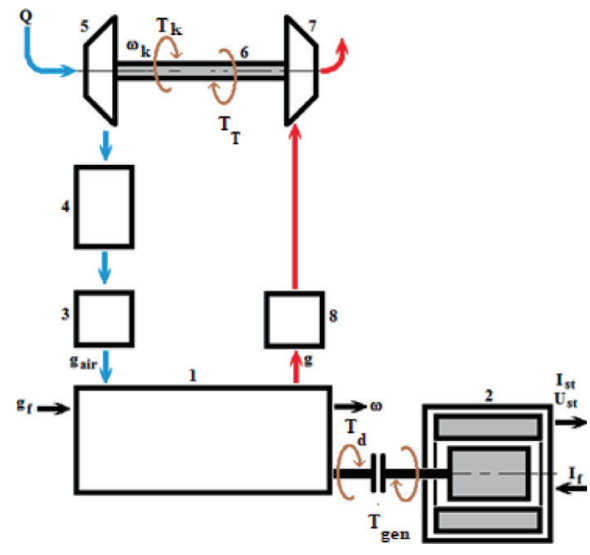

Fig. 1. Block diagram of a diesel generator set.

1 - diesel; 2 - synchronous generator; 3 -diesel intake manifold; 4 - intermediate air cooler; 5 - compressor; 6 - turbocharger shaft; 7 - gas turbine; 8 - exhaust manifold; $g_{\text {air }}-$ cyclic dose of air; $g_{f}-$ cyclic fuel supply; $g$ - cyclic dose of exhaust gases.

The deviation of the angular velocity of the diesel crankshaft (SG rotor) $\varepsilon$ :

$\varepsilon=\omega_{\max }-\omega_{\min }=A_{\omega}$.

It characterises the uneven flow of the working process along the cylinders of the diesel engine. It is determined by the technical condition of the fuel equipment, piston group, crank mechanism, valve system of the gas distribution mechanism. It causes oscillations of the angle $\Theta$ of the magnetic flux vector of the synchronous generator. The unevenness of the instantaneous angular velocity of the crankshaft of the diesel shaft of the synchronous generator (i.e., the angle $\Theta$ ) leads to a significant distortion in the spectral composition of the voltage and current of the generator. There- fore, the spectral composition of voltage and current can be a diagnostic parameter of both the generator itself and the primary diesel engine.

Coefficient of intra-cycle non-uniformity of change in angular velocity $\delta$ :

$\delta=\left(\omega_{\text {max }}-\omega_{\text {min }}\right) / \omega_{\text {middl }}$.

This coefficient is an integral indicator of the efficiency of an internal combustion engine (ICE).

When determining the indicator torque of a diesel engine $T_{i}$, the coefficient of technical condition $K_{l}$, which depends on the quality of the fuel system and the cylinderpiston group of the diesel engine, should be taken into account:

$T_{i}=T_{i}\left(B, h_{i}, \omega, t, K_{l}\right)$,

where:

$t$ - the operating time;

$h_{i}-$ the position of the high-pressure fuel pump rail;

$B$ - determines the amount of fuel (hourly consumption) entering the diesel cylinders. It is determined by the position $h$ of the rail of the high-pressure fuel pump. It characterises the current technical condition of the fuel equipment.

With regard to $T_{p}$ - the torque of diesel losses, the coefficient $K_{2}$ must be taken into account; it characterises losses due to pumping strokes, ventilation losses, friction losses in moving parts of a diesel engine:

$T_{p}=T_{p}\left(\omega, K_{2}\right)$. 
These coefficients determine the uniformity of power distribution across the cylinders and characterise the unevenness of the instantaneous angular velocity of the crankshaft (and, therefore, the synchronous generator shaft), the deviation of the angular velocity of the crankshaft $\varepsilon$ : $\varepsilon=\varepsilon\left(\varepsilon, K_{l}, K_{2}\right)$.

The effective torque $T_{d}$ of the diesel engine is pulsating due to outbreaks of fuel in the engine cylinders. It also causes deviation $\varepsilon$ of the angular velocity of the crankshaft of the diesel engine and oscillations of the angle $\Theta$ of the synchronous generator [16]. Therefore, it is obvious that the fluctuation of the angle $\Theta$ depends on the generator load current, the current and the instantaneous angular velocity of the diesel crankshaft.

\section{MATHEMATICAL MODEL OF SYNCHRONOUS GENERATOR}

The basis for the SG mathematical model is the system of equations for voltages in phase coordinates [19]-[21]. The basis for the mathematical model of synchronous generator is the system of ParkGoreva equations. As a high level of harmonics exists, the transient and emergency regimes are necessary to be investigated. Its mathematical model is reasonable to be realised in phase frame for stator and in $\mathrm{d}-\mathrm{q}$ frame for rotor. The voltage equations for the phase values are for all phases of the stator winding (A, B, C) and for the phases of the reduced three-phase circuits of rotor ( $f$ - the circuit of the excitation winding, $D$ - circuits of the damping winding along the axes $d$ and $q$ ) (Fig. 2).

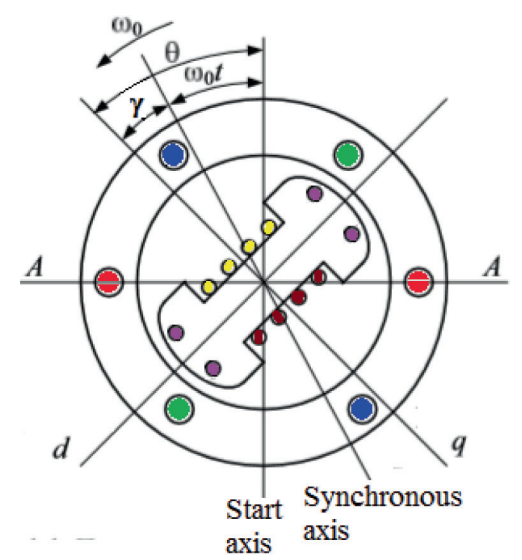

Fig. 2. Coordinate system of windings of the synchronous silent-pole generator.

$$
\left\{\begin{array}{c}
U_{A}(t)=R_{A} * i_{A}(t)+\frac{d \psi_{A}(t)}{d t} ; \\
U_{B}(t)=R_{B} * i_{B}(t)+\frac{d \psi_{B}(t)}{d t} ; \\
U_{C}(t)=R_{C} * i_{C}(t)+\frac{d \psi_{C}(t)}{d t} ; \\
U_{f}(t)=R_{f} * i_{f}(t)+\frac{d \psi_{f}(t)}{d t} ; \\
U_{D d}(t)=R_{D d} * i_{D d}(t)+\frac{d \psi_{D d}(t)}{d t} ; \\
U_{D q}(t)=R_{D q} * i_{D q}(t)+\frac{d \psi_{D q}(t)}{d t} ;
\end{array}\right.
$$

where $U(t)$ - the voltage of the circuit windings (A, B, C);

$R$ - resistance of the circuit windings;

$i(t)$ - current in the circuit windings;

$\psi(t)$ - flux linkage of the circuit windings.

System (6) is fulfilled with the last equation of the motion of diesel generator (1).

The flux linkages are expressed by means of the currents of stator phases, the currents of the rotor phases and correspondent inductances. For example, the flux linkage of the stator A phase is:

$$
\begin{aligned}
& \psi_{\mathrm{A}}(t)=L_{A} \cdot i_{A}(t)+M_{A B} \cdot i_{B}(t)+ \\
& +M_{A C} \cdot i_{C}(t)+M_{A f} \cdot i_{f}(t)+ \\
& +M_{A D d} \cdot i_{D d}(t)+M_{A D q} \cdot i_{D q}(t),
\end{aligned}
$$

where $L-$ the self-inductances of the machine windings;

$M$ - the mutual inductances of the machine windings. 
The flux linkages of $B, C, f, D_{d}$ and $D_{q}$ phases are similar.

In accordance with the reciprocity principle and assuming that steel has an infinitively high magnetic permeability the mutual inductances are equal. The constant inductances are those inductances the configuration of magnetic system of which stays constant at any position of the rotor. These are the inductances of all circuits of the rotor and mutual inductances between the rotor circuits. The rest inductances and mutual inductances are changed in accordance with the position of the rotor in space. Thus, the mutual winding inductances of the synchronous silent-pole generator are the periodic functions of the rotor rotation angle $\theta$. They are the harmonic time functions that should be notably taken into account while investigating transient processes.

$$
\begin{aligned}
& L_{A}, L_{B}, L_{C}, M_{A B}, M_{A C}, M_{B A}, \\
& M_{B C}, M_{C A}, M_{C B}=f(\theta) .
\end{aligned}
$$

The electromagnetic torque of the synchronous machine can be calculated as follows:

$$
T_{g e n}(t)=\frac{3 p_{\tau}}{2}\left(\psi_{d} \cdot i_{q}(t)-\psi_{q} \cdot i_{d}(t)\right) .
$$

For a reliable diagnosis of the current state of the D-SG electromechanical system, the required measurement accuracy should be at least $0.5^{0} \ldots 1.0^{0}$ from the angle of rotation $\theta$ of the engine crankshaft, and the angular velocity measurement accuracy $\omega$ should be at least $0.01 \mathrm{rad} / \mathrm{s}$. The frequency resolution for spectral analysis should be at least $0.01 \ldots 0.02 \mathrm{~Hz}$. To exclude random errors, measurements are carried out for at least $200 \ldots 300$ revolutions of the crankshaft.

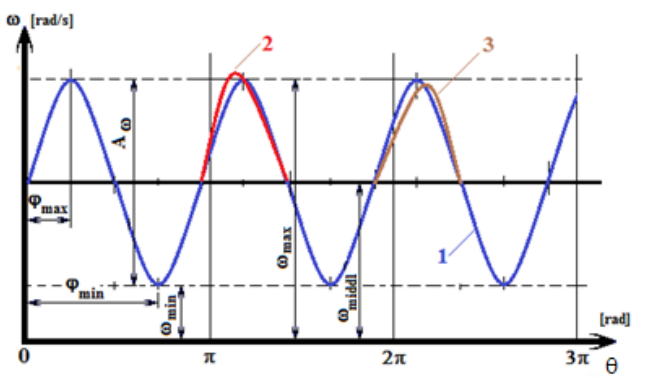

Fig. 3. The dependence of the angular instantaneous velocity $\omega$ on the angle of rotation $\varphi(\theta)$ of the crankshaft:

1 - with the same work processes in the engine cylinders;

2 - with an early flash and an excessive portion of fuel in one of the cylinders;

3 - with a late outbreak and a small portion of fuel in one of the cylinders.

The sensors of the top dead centre of the first cylinder and the instantaneous angular frequency of rotation are of the frequency type, based on a blocking generator. On the diesel flywheel at the TDC mark, a magnetic pin for the TDC sensor is mounted. The sensor of instantaneous angular rotation frequency (ARF) is placed above the teeth of the ring gear of the diesel flywheel. The number of teeth on the crown of this diesel model is 72 , i.e., they are located every $5^{0}$ degrees of the angle of rotation of the diesel crankshaft (SG rotor). Pulses from the ARF sensor go to the counter. At the other input of the counter, filling pulses from a quartz clock generator $(5 \mathrm{MHz})$ are received. Every $5^{0}$ of the angle of rotation of the crankshaft, the counter is reset. In this case, the error in measuring the instantaneous angular speed is not accumulated, and there are no averaging readings per revolution of engine crankshaft. Instant angular acceleration is recalculated for every $5^{0}$ of the rotation angle of the diesel crankshaft. This method allows accurately determining which cylinder causes changes 
in the instantaneous angular velocity and instantaneous angular acceleration. The number of diesel cylinders and the order of their operation is known in advance.

Figure 4 demonstrates a structural diagram of the diagnostics of a diesel generator set with a synchronous generator as a diagnostic sensor.

1 - diesel engine (DE); 2 - fuel pump of a high pressure - injection pump (IP); 3 proportional-integral-differential controller (PID); 4 - angular velocity sensor; 5 - voltage and power regulator of a synchronous generator (PID); 6 - synchronous generator (SG); 7 - voltage sensor; 8 - current sensor; 9 - frequency sensor; 10 - synchronous generator output; 11 - electric drive rail IP - step electric motor; 12 - diesel flywheel; 13 - TDC sensor of the first cylinder; 14 - diesel engine crankshaft angle sensor; 15 - microcontroller; 16 - spectrum analyser.

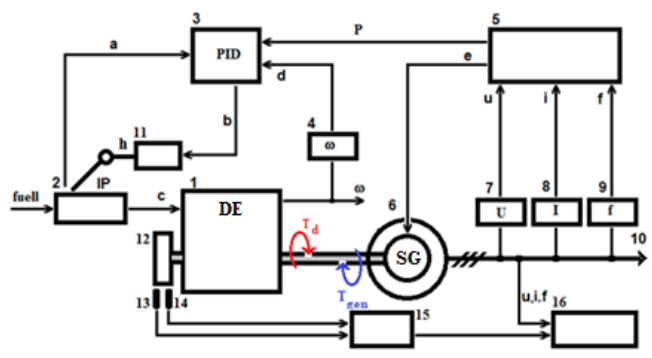

Fig. 4. Block diagram of a diagnostic system of a diesel generator set.

The output parameters of diesel engine 1 is effective torque $T_{d}$ and the angular velocity $\omega$. The disturbing effect is the torque of resistance $T_{\text {gen }}$ of the synchronous generator. The control action for the diesel engine is the h-rail of the injection pump. The control action for the SG is the excitation voltage, the input action (signal) is the effective torque $T_{d}$ and the angular frequency $\omega$ of the diesel engine. The disturbing effect of the $\mathrm{SG}$ is the stator phase current and stator voltage. The SG output param- eters - current, voltage and frequency are controlled by sensors 7, 8, 9. Information from them is fed to the voltage and power regulator 5. Regulator 5 controls the excitation voltage of the SG. In controller 5, the active component $\mathrm{P}$ of the $\mathrm{SG}$ power is calculated, according to which PID 3 regulates the fuel supply to the diesel cylinders using electric drive 11 of injection pump rail 2 . Therefore, the fluctuations in the angle $\Theta$ of the magnetic flux vector of the synchronous generator are caused not only by a change in the output stator currents, but also by an uneven rotation of the diesel crankshaft.

To carry out a spectral analysis of output voltages and currents, there is a computer with the appropriate software (spectrum analyser) 16 . The primary processing of information from TDC 13 frequency sensors and the rotation angle $\theta$ of the diesel crankshaft is carried out in microcontroller 15. The signal from it is transmitted to computer (spectrum analyser) 16. Therefore, the resulting spectrum of SG currents and voltages turns out to be tied to the angle of rotation of the diesel crankshaft. Knowing the order of operation of the diesel cylinders, it is possible to judge the technical condition of the cylinder-piston group, fuel equipment and gas distribution mechanism of each cylinder by the appearance of new harmonics and changes in the old ones. When conducting a spectral analysis of stator currents and SG voltages, first of all, it is necessary to take into account the energy-time parameters of the so-called characteristic frequencies. Characteristic frequencies are frequencies that are generated by various defects in the SG-D electromechanical system. For example, the four characteristic frequencies for bearings (the speed of rolling elements along the treadmills of the outer and inner rings of the bearing, the speed of the cage and the natural frequency of rotation of the bodies of rotation) are the frequencies 
that occur during the operation of the crank mechanism of a diesel engine, the frequencies that occur in case of misalignment and kink of the axes, violation of the gas distribution mechanism, non-symmetry of the electric load of the SG, etc.

It should be borne in mind that when working in an autonomous shipboard net- work of a synchronous generator, a load of the type of an asynchronous electric motor with semiconductor converters (frequency converters, etc.) may cause additional harmonics, which will require an additional analysis of the current and voltage spectra.

\section{RESULTS OF CALCULATIONS}

The results of the presented mathematical apparatus, equations $(1,2,7,8,9)$, were analysed on the basis of mathematical modelling of the diesel generator model in the MATLAB Simulink software. In order to simplify the modelling process, we will present it in the form of seven stages (blocks).

1. The first block models variable coefficients $\mathrm{L}, \mathrm{M}$ in equations $(7,8)$ to determine flux linkage.

2 . The second unit simulates the flux values obtained on the basis of the coefficient values $\mathrm{L}, \mathrm{M}$.

3. The third block simulates the voltage of the stator windings according to the equations of the system (6).

4. The fourth block simulates the voltage of the rotor windings according to the equations of the system (6).

5. The fifth block simulates the system of equations of a synchronous generator (6).

6. The sixth block simulates the diesel equations (2).

7. The seventh block simulates the diesel generator system according to the equation of motion (1).

Results of calculations and further analysis of the spectrum of voltage harmonics are presented on the spectrogram (Fig. 5).

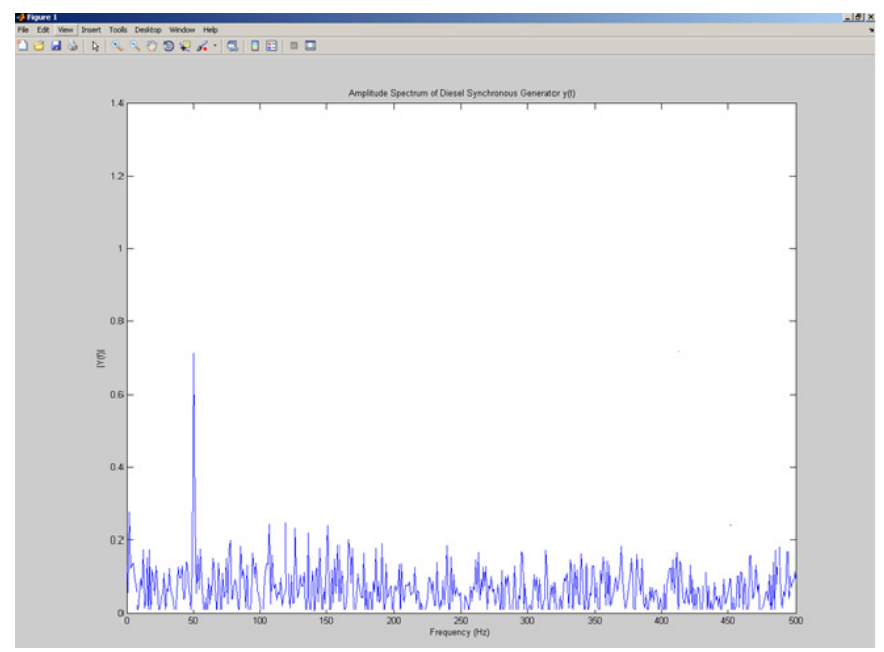

Fig. 5. The spectrogram of the analysis of the model of the diesel generator set. 


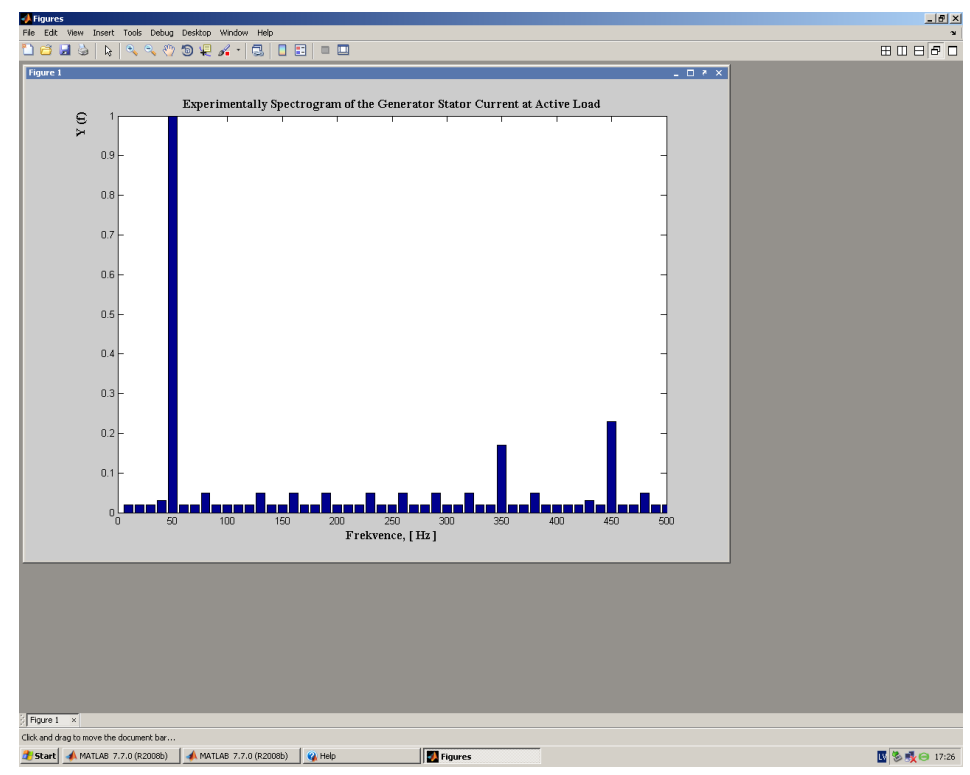

Fig. 6. Experimentally taken from the spectrogram of the stator current of the generator at active load.

In Fig. 6, the appearance of the 7th harmonic $(350 \mathrm{~Hz})$ and the 9th harmonic $(450$ $\mathrm{Hz}$ ) is clearly visible. The amplitude of the fundamental harmonic at $50 \mathrm{~Hz}$ is taken as a conventional unit. The appearance of these harmonics indicates an uneven air gap in the bore of the generator stator. Uneven air gap can be caused by unsatisfactory technical condition of the generator bearings and, as a result, skew of the rotor in the bore of the generator stator.

\section{CONCLUSIONS}

1. Analysing the received electric parameters of non-uniformity of the rotating moment, angular velocity, angular acceleration and spectral power structure of output currents and pressure and comparing them with reference values, it is possible to evaluate an actual condition of systems and units - both the piston machine and the synchronous machine.

2. The most effective technical diagnostics of electric machines and units mechanically connected to them is carried out in transitive modes.

3. The change in the previous harmonics parameters and the appearance of new ones clearly demonstrate emerging defects in the "engine synchronous generator" system.

4. The use of the synchronous machine in a diesel engine generating and compressor installations as a multipurpose diagnostic sensor is presented. Analysing the received electric parameters of non-uniformity of the rotating torque, angular velocity, angular acceleration and spectral power structure of output currents and pressure, as well as comparing them with reference values, it is possible to estimate an actual condition of systems and units - both the piston machine and the synchronous machine. 


\section{REFERENCES}

1. Lamaris, V. T., \& Hountalas, D. T. (2010). A General Purpose Diagnostic Technique for Marine Diesel Engines - Application on the Main Propulsion and Auxiliary Diesel Units of a Marine Vessel. Journal of Energy Conversion and Management, 51 (4), 740753.

2. Charles, P., Sinha, J. K., Gu, F., Lidstone, L., \& Ball, A. D. (2009). Detecting the Crankshaft Torsional Vibration of Diesel Engines for Combustion Related Diagnosis. Journal of Sound and Vibration, 321, 3-5.

3. Lus, T. (2012). Marine Diesel Engine Diagnostics in Operating Conditions. Diagnostika - Applied Structural Health Usage and Condition Monitoring, 2 (62), 43-47.

4. Lus, T. (2011). Vibro-Acoustic Methods in Marine Diesel Engines Diagnostics. Journal of KONES Powertrain and Transport, 18 (3), 193-200.

5. Zhixiong, L., Xinping, Y., Chengqing, Y., \& Zhongxiao, P. (2012). Intelligent Fault Diagnosis Method for Marine Diesel Engines Using Instantaneous Angular Speed. Journal of Mechanical Science and Technology, 26 (8), 2413-2423.

6. Hansen, J. F., Adnanes, A.K., \& Fossen, T.I. (2001). Mathematical Modelling of DieselElectric Propulsion Systems for Marine Vessels. Mathematical and Computer Modelling of Dynamical Systems, 7 (1), 323-355.

7. Luo, L., Gao, L., \& Fu, H. (2011). The Control and Modeling of Diesel Generator Set in Electric Propulsion Ship. Information Technology and Computer Science, 2, 3137.

8. Gasparjan, A., Greivulis, J., \& Terebkov, A. (2001). Diagnostic simulator of the marine diesel engines. In ICERS5 5th International Conference on Engine Room Simulators. Simulator-Aided Education \& Training in the New Millennium. Singapore Polytechnic.
9. Gasparjan, A., \& Terebkov, A. (2005). Problems of electric energy quality in ship diesel engine - Generator installations. Proceedings of the 9th International Conference. Transport Means. Kaunas University of Technology.

10. Gasparjan, A., \& Terebkov, A. (2017). Multifunctional system of the diesel engine - generator diagnostics in ship installations. Scientific Proceedings of Riga Technical University. Power and Electrical Engineering, 16. RTU. Riga.

11. Lesinskis, I., Gasparjans, A., \& Terebkovs, A. (2009). Results of ship's engine vibromonitoring. Proceeding of 11th International Conference "Maritime Transport and Infrastructure”. Riga: Latvian Maritime Academy, 147-151.

12. Nedelko D., Urbahs A., Turko V., Urbaha M., Carjova K., \& Nagaraj P. (2019). Assessment of the Limits of Signs of Health and Usage Monitoring System for Helicopter Transmission. Procedia Computer Science, 149, 252257.

13. Urbahs, A., Banovs, M., Carjova, K., Turko, V., \& Feshchuk, J. (2017). Research of the Micromechanics of Composite Materials with Polymer Matrix Failure under Static Loading Using the Acoustic Emission Method. Aviation, 21 (1), 9-16.

14. Trigeassou, J. C. (2011). Electrical Machines Diagnosis. Wiley-ISTE.

15. Panadero, R.P, Linares, J.P., Alarcon, V.C., \& Sanchez, M.P. (2013). Review Diagnosis Methods of Induction Electrical Machines based on Steady State Current. Available at www.aedie. org/11chlie-papers/263-Puche.pdf. 
16. Gasparjan, A., Terebkov, A., \& Terebkova, M. (2006). The use of results of spectral analysis of synchronous generator output voltage for technical diagnostics. In International Conference on Industrial Technology ICIT2006. Indian Institute of Technology Kharagpur. Bombay.

17. Faris, W. F., Rakha, H. A., Kafafy, R. M., Idres, M., \& Elmoselhy, S. (2012). Diesel Engine Analytical Model. International Journal of Scientific \& Engineering Research, 3 (8).

18. Hui, C., Peili, W., \& Jundong, Z. (2013). Modeling and Simulation of Working Process of Marine Diesel Engine with a Comprehensive Method. International Journal of Computer Information Systems and Industrial Management Applications, 5, 480-487.
19. Gasparjan, A., Terebkov, A., \& Zhiravetska, A. (2017). Monitoring of electro-mechanical system dieselsynchronous generator. In 5th International Conference on Power Engineering, Energy and Electrical Drives. IEEE P0werENG, IES, May, Riga.

20. Zhiravetska, A., Gasparjans, A., \& Terebkov, A. (2017). Monitoring of current technical condition of vessel diesel-generator installation. In EPE'17, ECCE EUROPE (pp. 1-7), 11-14 September, Warsaw, Poland.

21. Ivanov-Smolenski, A. B. (1980). Electric machines. M.: Energija (in Russian). 